\title{
Weight, Diet, and Physical Activity-Related Beliefs and Practices Among Pregnant and Postpartum Latino Women: The Role of Social Support
}

\author{
Pamela L. Thornton, ${ }^{1,8}$ Edith C. Kieffer, ${ }^{2}$ Yamir Salabarría-Peña, ${ }^{3}$ \\ Angela Odoms-Young, ${ }^{4}$ Sharla K. Willis, ${ }^{5}$ Helen Kim, ${ }^{6}$ \\ and Maria A. Salinas ${ }^{7}$
}

\begin{abstract}
Published online: 14 March 2006
Objectives: Eating and physical activity patterns may contribute to excessive pregnancy weight gain and postpartum retention that increase the risks of obesity and diabetes for both Latino mothers and their children. Social support is an important health determinant and may affect health-related beliefs and behaviors. The objective of this study was to investigate the influence of social support on weight, diet, and physical activity-related beliefs and behaviors among pregnant and postpartum Latinas. Methods: A community-based participatory project, Promoting Healthy Lifestyles among Women, was conducted in southwest Detroit to plan interventions aimed at reducing risks of obesity and type 2 diabetes. Qualitative analyses of in-depth semistructured interviews with dyads of 10 pregnant and postpartum Latinas, and 10 people who influenced them were conducted. Results: Husbands and some female relatives were primary sources of emotional, instrumental, and informational support for weight, diet, and physical activity-related beliefs and behaviors for Latina participants. Holistic health beliefs and the opinions of others consistently influenced Latinas' motivation and beliefs about the need to remain healthy and the links between behavior and health. Absence of mothers, other female relatives, and friends to provide childcare, companionship for exercise, and advice about food were prominent barriers that limited women's ability to maintain healthy practices during and after pregnancy. Conclusion: The findings support evidence that low-income, recently immigrated pregnant and postpartum Latinas could benefit from community-based, family-oriented interventions that provide social support necessary to promote and sustain healthy lifestyles.
\end{abstract}

KEY WORDS: Social support; pregnancy; Latinas; diet and weight; physical activity.

\footnotetext{
${ }^{1}$ Institute for Social Research, University of Michigan, Ann Arbor, Michigan.

${ }^{2}$ University of Michigan School of Social Work, 1080 S. University, Ann Arbor, Michigan.

${ }^{3}$ Health Services Research and Evaluation Branch, Centers for Disease Control and Prevention, Atlanta, Georgia.

${ }^{4}$ Public and Community Health Program, Northern Illinois University School of Allied Health, Dekalb, Illinois.

${ }^{5}$ Ohio State University School of Public Health, Columbus, Ohio. ${ }^{6}$ University of Michigan School of Social Work, 1353 West Winona, Unit 1, Chicago, Illinois.

${ }^{7}$ University of Michigan School of Public Health, Ann Arbor, Michigan.
}

\section{INTRODUCTION}

Obesity and type 2 diabetes are increasing concerns for Latino women of childbearing age in the U.S., with significant disparities in prevalence

\footnotetext{
${ }^{8}$ Correspondence should be addressed to Pamela L. Thornton, W.K. Kellogg Foundation Scholar in Health Disparities, Institute for Social Research, University of Michigan, Ann Arbor, Michigan 48106-1248; e-mail: pthornt@umich.edu.
} 
compared to non-Hispanic White women, and serious health, social, and economic consequences for women, their families, and communities (1-4). Excessive pregnancy weight gain and postpartum retention associated with eating and physical activity patterns before, during, and after pregnancy may increase the risks of developing obesity and diabetes for both mothers and their children (5-8). Understanding factors contributing to these patterns is essential for planning and implementing effective interventions, yet few studies have been conducted with Latinas $(6,8)$.

Building upon a smaller, earlier study (9), Promoting Healthy Lifestyles among Women [Promoviendo Estilos de Vida Saludables entre Mujeres] was a community-based participatory research project conducted to plan programs and policies aimed at reducing risk factors for obesity and diabetes among pregnant and postpartum African American and Latino women in Detroit. Participants identified a wide range of individual, social, and physical environmental barriers to adopting or maintaining healthy lifestyles during and after pregnancy, and recommended strategies for reducing those barriers (10). The importance of social influence and social support were prominent themes identified by participants.

Although a variety of definitions have been used to assess the concept of social support, it is usually classified as either perceived or received support, and as three major types, each of which may be experienced as positive or negative: 1) emotional (e.g., feeling loved, appreciated, and valued), 2) informational (e.g., advice or guidance), and 3) instrumental (e.g., tangible assistance) $(11,12)$. Social support is also a well-known determinant of psychological and physical health (13-15). It is linked to a number of healthrelated behaviors during pregnancy such as drinking, smoking, and substance abuse $(11,16-18)$ as well as maternal and infant outcomes such as labor complications and birth weight $(11,12,19)$.

For Latinas, social relationships may have particular relevance for health since the extended family has traditionally played an integral role in daily life $(20,21)$. Importantly, social networks can be enlisted by individuals to meet various emotional, informational, and material needs, especially during times of transition and financial strain. As such, low-income, pregnant and postpartum Latino women may require support in more frequent and diverse ways than usual to stay healthy. Several recent studies indicate that the social networks of ethnic-minority women may affect their health-related beliefs and behaviors $(22-28)$ but few studies have focused on pregnant and postpartum Latinas (9). The objective of this study was to investigate the influence of social support on weight, diet, and physical activity-related beliefs and behaviors among pregnant and postpartum Latinas.

\section{METHODS}

Promoting Healthy Lifestyles among Women [Promoviendo Estilos de Vida Saludables entre Mujeres], a community-based participatory research partnership affiliated with the Detroit Community Academic Urban Research Center, was conducted in 2000-2001 in eastside and southwest Detroit (29). It was guided by a Steering Committee of community resident women of childbearing age and representatives of community, academic, and health-related organizations $(10,30)$. The project was conducted in three sequential phases beginning with in-depth semistructured individual interviews with pregnant and postpartum Latino and African American women and people who they identified as influential in their weight, diet, and physical activity beliefs and practices (10). During the second and third project phases, results from these interviews were reviewed by focus groups of pregnant and postpartum women who confirmed and extended the findings of the first phase interviews, and by program and policy leaders, who reviewed the women's recommended intervention strategies, and added their own (30). All research protocols and materials were approved by the University of Michigan Institutional Review Board.

Data for the current study were derived from analyses of the semistructured individual interviews conducted with 10 Latino dyads during the first phase of the project. These included five pregnant and five postpartum women and 10 people identified by the women as most likely to influence their beliefs and practices. These interviews were conducted in southwest Detroit, an ethnically diverse community in which approximately $35 \%$ of the population is Latino, including many recent immigrants from Mexico (31).

Spanish-speaking Latino pregnant and postpartum community residents who were at least 18 years of age were recruited by flyers and inperson by trained female recruiters at a federally qualified health center, a Special Supplemental Nutrition Program for Women, Infants, and Children 
(WIC) clinic, and a "Baby Fair" run by community organization partners. Pregnant women were recruited at any point during pregnancy, and postpartum women were recruited at approximately 6-12 weeks following delivery. During the initial eligibility assessment, women identified a person whom they believed influenced their dietary and physical activity practices. The recruiter later contacted both the women and the influential persons by telephone to confirm their interest in participating and to schedule interviews.

The project Steering Committee designed a semistructured interview guide to elicit participants' beliefs and attitudes about weight, pregnancy-related weight gain, and postpartum weight retention, diet, and physical activity; and factors influencing eating and physical activity patterns, including personal, family, and community barriers, during and after pregnancy. Participants were also asked to identify possible ways for reducing these barriers. All interviewers were Latino women. Interviewers were trained by the academic research team, who had extensive experience conducting communitybased participatory research in Latino and African American communities using qualitative research methods. The training included introductions to, and practice with, all study materials and procedures, and practice interviews with a native Spanish-speaking member of the research team.

Informed consent was obtained at the time of the interview. All interviews were conducted in Spanish. The same person interviewed a dyad to facilitate exploring variations in perceptions expressed in the two interviews. Interviews with the pregnant and postpartum women were conducted first. Their interviews were conducted in locations where they were most comfortable and where confidentiality could be ensured (i.e., homes, restaurants, etc.). Since most influential persons were husbands living in the same household as the pregnant and postpartum participants, interviews with influential persons were conducted in public places to ensure confidentiality and increase rapport. Each participant received $\$ 25$ at the completion of their $60-90 \mathrm{~min}$ interview. No information from the women's interviews was shared with their influential persons or vice versa. All interviews were audio tape-recorded, transcribed verbatim in Spanish, translated into English, and reviewed for accuracy.

Detailed field notes were taken by the interviewer during and immediately after the interviews to document nonverbal cues and the social- environmental contexts of the interviews. These notes were incorporated into the final transcript, which was entered as a text document into Atlas/Ti software (32) to manage data analysis. An inductive analytic procedure was followed (33). Transcripts were reviewed line-by-line by a Spanish-speaking graduate student and Spanish-speaking members of the research team to identify initial codes/categories in the data and intercoder reliability was determined. Core categories were compared and developed into themes. Codes and categories were reviewed and refined at weekly research meetings and after a meeting with the project Steering Committee, followed by final review and final coding of the transcripts. For this study, data within and across categories were reviewed to construct social support themes and identify characteristic patterns in social support and health-related beliefs and behaviors based on meanings that emerged from the data. Results were then analyzed by dyad and summarized by type of participant (i.e., pregnant, postpartum women, influential person). Our analysis revealed multiple themes that could be classified into three broad dimensions or types of support that have frequently been discussed in the literature (i.e., informational, emotional, and instrumental).

\section{RESULTS}

\section{Participant Characteristics}

Eight dyads were participant-husband pairs; two dyads were female only (one mother and one sister-in-law). The mean age of pregnant and postpartum women was 27.1 years (range 21-36). They had a mean of 1.5 children (range $0-4$ ), (two children lived with relatives in Mexico). Household size averaged 5.1 people (range 3-10). All of the women were married and reported being housewives. One Latina also worked as a laborer outside the home. The husbands worked as construction workers, a painter, and handymen. All participants, including influential persons, were born in Mexico. The pregnant and postpartum women had lived in the U.S. an average of 3.3 years while influential persons had lived in the U.S. an average of 5.2 years.

As stated, three social support dimensions emerged from the data that influenced participants' weight, diet, and physical activity-related beliefs. Informational support in these data represented advice, information, or guidance; emotional support 
represented encouragement, criticism, or desire to please; and instrumental support represented tangible assistance (material, financial, or physical). A summary of the findings that are outlined in more detail in the next sections, suggests the following: 1) Informational and emotional support of husbands were the most important and consistent influence on participants' weight, eating, and physical activity practices; 2) Both eating and physical activity patterns were influenced by cultural beliefs and family rituals concerning safe and appropriate foods and physical activities during and after pregnancy; 3) Absence of mothers and female relatives to provide companionship and advice about food was evident; and, 4) Geographic distance was the primary reason for Latinas being separated from close female-centered networks, which seemed to interrupt the transmission of health-related beliefs and behaviors.

\section{Influences of Social Support on Weight-Related Issues}

Table I summarizes the social support dimensions, major themes, and selected quotes related to the influences of social support on weight-related issues. Pregnant and postpartum women reported being primarily influenced by their husbands on issues concerning weight (Table I). The informational support given by husbands revealed a strong belief system that weight and health status are interconnected. Health, as a concept, was viewed holistically whereby a balance between physical and emotional states determines well-being. For example, one husband recalled telling his wife: "you can't let yourself have any excess weight... So you can feel healthy and feel good about yourself." Consequently, husbands believed that being overweight threatened various aspects of individual and married life, particularly concerning motivation and energy. Also important to both husbands and women was a physically fit and attractive body. Advice guided by this belief system sometimes fostered a sense of urgency to lose weight and avoid being "fat." Therefore, most participants attempted to avoid excess weight gain during the prenatal and postnatal periods in order to maintain good health and please their husbands. However, these attempts were usually abandoned by participants and discouraged by husbands during pregnancy for the sake of having a "big" or healthy baby.

Although secondary sources of guidance came from a mother-in-law and information disseminated in doctors' offices, these influences were not prominent. For example, a few pregnant women learned about prenatal weight guidelines from books and television programs in a medical clinic. However, these women did not say they had received advice about weight directly from a physician. Being separated from extended family and female relatives, such as biological mothers who lived in Mexico, was an additional barrier to obtaining advice. One respondent had an influential mother-in-law who lived in the U.S. and functioned as a substitute mother. She advised her daughter-in-law to avoid repeating the mistake older women make of gaining weight and becoming ill, with such comments as: "Mi'ja, give it your all and don't let yourself get fat like we did... avoid getting fat."

The most influential emotional support concerning weight issues was given by husbands. As a result, nearly all of the pregnant and postpartum women

Table I. Social Support and Weight-Related Issues (Dimensions, Sources, Themes, and Selected Quotes)

\begin{tabular}{|c|c|c|}
\hline Dimensions & Sources & Major themes and selected quotes \\
\hline \multirow[t]{3}{*}{ Informational } & Husbands $^{a}$ & Interconnection between weight and health status \\
\hline & & He says, "you're already a little fat. Do some exercise." \\
\hline & Doctor's office & Follow medical advice \\
\hline \multirow[t]{3}{*}{ Emotional } & Husbands $^{a}$ & Criticism or negative feedback \\
\hline & & $\begin{array}{l}\text { It [her losing weight] is important for both of us ... we wouldn't have any more problems ... have } \\
\text { anything to argue about. }\end{array}$ \\
\hline & & $\begin{array}{l}\text { Sometimes I listen to him and sometimes I say, if he loves me, he should love me like this. I am not that } \\
\text { fat. He exaggerates. }\end{array}$ \\
\hline Instrumental & & None reported. \\
\hline
\end{tabular}

${ }^{a}$ Represents the most influential source of support for the corresponding dimension. 
wanted to make their husbands happy by either not gaining or losing weight. Some participants believed that their husbands gave negative support that involved harsh criticism and humiliation: "He tells me that I'm real fat and to go on a diet... that if I don't lose weight, he will leave me for another woman." In such instances, participants' excess weight appeared to fuel marital discord but no reported changes in weight. Similarly, some family members (i.e., brothers and sisters) were remembered as being judgmental, which resulted in fears about weight, disapproval, and subsequent name calling. A respondent explained: "I want to gain weight a little, but at the same time not a lot because they'll start on me, 'how chubby, how chubby." The one Latina who worked outside the home was also the only respondent who reported having a supportive female friend to provide encouragement to lose weight. It is notable that no instrumental support was mentioned for weight issues that could be distinguished from the instrumental support provided for other health behaviors, particularly physical activity and exercise.

\section{Influences of Social Support on Diet and Eating Patterns}

According to the participants, the informational support that most influenced their diet and eating patterns came from their small network of female relatives and friends in the U.S. (Table II). This was important since several participants reported not knowing how to cook some foods when they moved away from biological families and their mothers' advice in Mexico to live with husbands in the U.S. These women provided advice that helped the women change unhealthy diets, particularly during pregnancy. Female in-laws suggested eating more fruit, beans, lentils, vegetables, and stew, and avoiding "contaminants" or "too many ingredients."

Secondary sources of informational support that influenced women's eating patterns included their husbands' preferences and traditional cultural beliefs. These "very old traditions" such as avoidance of foods defined as "cold" and indulgence of cravings were transmitted by both male and female family members. One husband explained: "if she doesn't

Table II. Social Support and Diet/Eating Patterns (Dimensions, Sources, Major Theme, and Selected Quotes)

\begin{tabular}{|c|c|c|}
\hline Dimensions & Sources & Major themes and selected quotes \\
\hline \multirow[t]{8}{*}{ Informational } & Female & Eat healthy foods \\
\hline & relat./friends ${ }^{a}$ & I tell her, instead of eating other things, eat fruit. She eats a lot of fruit. \\
\hline & & $\begin{array}{l}\text { Because my husband's mother is like that ... for everything she combines fruit and vegetables and I } \\
\text { learned from her. }\end{array}$ \\
\hline & & Lack of access to relatives' advice \\
\hline & & $\begin{array}{l}\text { For example, here }[\text { U.S.] ... not knowing how to prepare them ... how to mix in a fruit or a vegetable } \\
\text { that you don't like too much. Also not knowing to use ingredients that are good for you. }\end{array}$ \\
\hline & & Follow traditions and food avoidance \\
\hline & & $\begin{array}{l}\text { They say when one eats watermelon, jicama, beans, it's real bad after the pregnancy, the birth ... the } \\
\text { womb gets cold ... they tell me that you shouldn't even eat avocado... it's very bad because it's too } \\
\text { cold }\end{array}$ \\
\hline & Husbands & $\begin{array}{l}\text { I usually tell her not to eat too much ... eat more vegetables... I forbid her from eating cookies, cake, } \\
\text { and other things that make people fat. }\end{array}$ \\
\hline \multirow[t]{4}{*}{ Emotional } & Husbands $^{a}$ & Eat with family \\
\hline & & $\begin{array}{l}\text { We eat when my husband gets home... We eat late. Not advice, but he does encourage me to do things. } \\
\text { Sometimes I don't want anything and he makes it so we can eat together. }\end{array}$ \\
\hline & Family/friends & Please others \\
\hline & & Sometimes it's only to please people... I do eat it to satisfy others \\
\hline \multirow[t]{4}{*}{ Instrumental } & Husbands $^{a}$ & Access to healthy and unhealthy food \\
\hline & & $\begin{array}{l}\text { When my husband hasn't worked for a prolonged number of days ... we don't buy everything we should } \\
\text { be buying... I would like to buy more things to eat so that our diet can be more balanced ... Yes, I } \\
\text { always wish I could buy more vegetables and more fruit. } \\
\text { My wife drinks juice. I buy her a gallon of juice every week ... so it can last.... } \\
\text { I say, "bring me some ice cream." And he brings me some ice cream. }\end{array}$ \\
\hline & Formal agency & Access to healthy food \\
\hline & & $\begin{array}{l}\text { WIC gives help, but it's not enough ... They only give five juices per month ... Orange juice, pineapple } \\
\text { juice, } V 8, \ldots \text { they give cheese, two pounds ... two dozen eggs ... five gallons of milk a month ... And } \\
\text { a pound of beans. }\end{array}$ \\
\hline
\end{tabular}

${ }^{a}$ Represents the most influential source of support for the corresponding dimension. 
eat what she craves, that might harm the baby." In an effort to live a healthy lifestyle during and after pregnancy, husbands typically demanded that their families eat mostly homemade meals instead of meals prepared "in the street" where food was "not healthy." They also gave participants advice about food selections (e.g., reducing sweets, increasing fruit and vegetables). At the same time, husbands' food preferences influenced many participants to eat more meat than they had eaten before marriage, a habit participants believed had negative consequences for weight.

Emotional support given by husbands was reported as the strongest influence on women's eating patterns. Wanting to please husbands was an important motivating factor in what women chose to eat as explained by one respondent: "Yes, he likes it if I eat more healthy ... it makes me feel good that he's happy." Most women said they looked forward to the companionship that came with eating meals with their husbands on a daily basis. Thus, mealtime patterns and food choices were highly influenced by the work schedules and preferences of husbands. Being alone, or worrying about husbands when they were away from home, led women to irregular eating patterns or a tendency to either under- or overeat. Some husbands identified the influence their companionship had on the eating practices of their wives: "She worries a lot about me ... if I don't eat before leaving the house, she will not eat either."

Family rituals and events with friends were secondary sources of emotional support that influenced the eating patterns of both the women and their husbands. Weekends represented times when families ate at fast food restaurants and spent time together outside the home. A husband explained: "From Monday through Friday we eat homemade food. On Saturday and Sunday we go out to eat hamburgers, hot dogs ... We go to McDonalds, to Burger King, and to many other restaurants." Both women and their husbands also described social influences to overeat at parties and celebrations hosted by family and friends, often related to pleasing others: "whenever someone offers us something to eat, to be polite, we don't refuse... we do that to be courteous or for the sake of our friendship."

Although husbands' instrumental support was reported by participants as the most influential source of material aid that affected their diet and eating patterns, household incomes were also important. Some participants reported eating or buying fewer healthy foods when they experienced financial constraints due to husbands' seasonal work schedules and living with extended family. During financial distress, fruits and vegetables were typically the first to be sacrificed from food purchases instead of beans, lentils, and, particularly meats, because of husbands' preferences.

Despite good intentions and ongoing concerns about women's weight status, some husbands brought home fattening foods on a regular basis for their wives to enjoy or to satisfy their cravings. Several husbands also brought home healthy foods such as bags of vegetables and fruit juices, especially when financial constraints were not a problem. Formal agencies, such as the WIC program, provided access to some healthy foods, but one participant reported that the food quantities were "not enough."

\section{Influences of Social Support on Physical Activity and Exercise}

Overall, participants reported that their husbands provided the most important source of informational support for increasing physical activity (Table III). They consistently told their wives to exercise to lose pregnancy weight so they would not become fat or ill and this advice usually resulted in women engaging in more physical activity. The type of informational support that women received to exercise varied by their pregnancy status. During pregnancy, and immediately postpartum, they were advised and expected by both husbands and extended family to limit strenuous physical activity. Lifting heavy objects was strongly discouraged to protect the baby and mother's health. Adhering to cultural norms regarding a new mothers' need to rest for at least 1-month postdelivery was also expected by most participants and influential persons. However, instruction about this norm was translated to participants by older female relatives, such as mothers-in-law, and not by husbands or others. Medical advice to walk during pregnancy also influenced participants' beliefs about the types of physical activity that foster a healthy pregnancy and delivery.

Husbands provided both emotional and instrumental support to exercise. They encouraged women to exercise and provided companionship to help them do so. Since active lifestyles in Mexico involving sports and daily walks were valued by women and their families, engaging in such activities after pregnancy was perceived as a natural and desirable 
Table III. Social Support and Physical Activity/Exercise (Dimensions, Sources, Major Themes, and Selected Quotes)

\begin{tabular}{|c|c|c|}
\hline Dimension & Source & Major themes and selected quotes \\
\hline \multirow[t]{7}{*}{ Informational } & Husbands $^{a}$ & Maintain holistic health \\
\hline & & I don't say this to offend you, but exercise so you can feel good. \\
\hline & Husbands/ & Limit heavy lifting/follow cultural norms \\
\hline & $\begin{array}{l}\text { extended } \\
\text { fam. }\end{array}$ & Before and after pregnancy, it is highly recommended that they not do heavy lifting. \\
\hline & & $\begin{array}{l}\text {... she tells me that it's very recommendable that you be a month without much activity ... A month in } \\
\text { which you have a little rest so you can recover. }\end{array}$ \\
\hline & Doctor & Walk for healthy pregnancy \\
\hline & & $\begin{array}{l}\text { The doctor told her... "look Isabel, if you get pregnant again, please walk. Otherwise, you are going to } \\
\text { struggle again." }\end{array}$ \\
\hline \multirow[t]{3}{*}{ Emotional } & Husbands $^{a}$ & Encouragement and companionship \\
\hline & & $\begin{array}{l}\text { "Let's go walk, get some exercise'... my husband is the one that motivates me the most." } \\
\text { My husband and I sometimes go to the park ... I go play tennis with him. }\end{array}$ \\
\hline & Friends ${ }^{a}$ & If I had a companion, I'd go out to walk, right? But all by myself I don't really want to go out very much. \\
\hline \multirow{4}{*}{ Instrumental } & Husbands $^{a}$ & Access to childcare \\
\hline & & $\begin{array}{l}\text { When I'm at home, I help her with the baby, and she sometimes goes out for a walk or she simply walks to } \\
\text { the store. }\end{array}$ \\
\hline & & Limit strenuous activity \\
\hline & & $\begin{array}{l}\text { When we go out, I always carry the girl, always. Or, I put her in or take her out of the car so that she doesn't } \\
\text { go getting in and out with her. }\end{array}$ \\
\hline
\end{tabular}

${ }^{a}$ Represents the most influential source of support for the corresponding dimension.

thing to do. A respondent explained: "What is my motivation? ...feeling good ...feeling healthy. It's my first motivation. And my second motivation ... is my husband ... because he likes athletics so much." Several women described walking in the park or playing sports accompanied by their husbands. For other women, social isolation or a lack of support from husbands or friends with whom to exercise were barriers to getting regular exercise.

Childcare was another form of instrumental support, the presence or absence of which strongly affected women's physical activity. Husbands occasionally watched their children so their wives could exercise, but this occurrence appeared to be rare and restricted to evenings or weekends when husbands were home from work. Husbands also routinely provided support that helped participants avoid lifting heavy objects and engaging in strenuous activities during pregnancy.

\section{DISCUSSION}

This study contributes useful information to extend knowledge and contribute to understanding of the interplay of social support and health-related behaviors among Latino women during the pregnancy and postpartum periods. A dyad approach to collecting and analyzing data revealed the importance of social support in shaping beliefs and behaviors re- lated to weight, diet, and physical activity. Our analysis identified the categories and sources of support that were most available for the sample, as well as existing gaps in support. Such findings can better inform culturally relevant intervention strategies to promote healthy lifestyles among similar groups of low-income women.

In this study, the informational and emotional support of husbands was the most important and consistent influence on weight, eating, and physical activity practices. Husbands' concerns and advice about their wives being overweight or "fat" were frequently motivated by a holistic perspective about health whereby physical and mental states were seen as interrelated. The women valued both these holistic health beliefs and their husbands' opinions. Taken together, these factors influenced the participants' motivation and beliefs about the need to lose weight and remain healthy. Previous studies have also found that pregnant Mexican-born women value holistic health practices, particularly balancing physical activity and rest, avoiding stress, and eating healthy $(34,35)$.

Both eating and physical activity patterns of study participants were influenced by cultural beliefs concerning safe and appropriate foods, physical activities during and after pregnancy, and family rituals (e.g., eating out on weekends, walking or going to the park together). However, women's ability to adopt what they considered healthy eating and 
exercise habits were mostly affected by the support provided by their husbands. In most instances, husbands' income for groceries, and companionship for eating meals and exercising, influenced participants to eat regularly, and to engage in physical activity occasionally. Similarly, lack of instrumental support from husbands often inhibited women's healthy practices, an example being when husbands purchased fast foods or fattening snacks for their wives. During times of financial shortages or husbands' unemployment, participants would often forego purchasing healthy foods, especially fresh fruits and vegetables, in favor of foods, such as meat, that husbands preferred. Additionally, the lack of other types of tangible support, such as childcare or housekeeping that could free women's time for exercise, was a serious barrier to independent activities outside the home or with others.

The absence of female relatives and mothers to provide companionship for activities and advice about food was a prominent theme in this study. Some participants reported that low interaction with experienced women limited their knowledge of ways to cook and eat healthy, and increased feelings of isolation. Social support from family and friends has been shown to be an important contributor to the healthy eating habits of many Latino families (21, 28, 36). Further, the companionship provided by close others, especially friends, has been found to improve levels of physical activity among Latinas (9, $23,25)$. Similar to the findings of other studies (9, $11,22,35,37)$, we found that geographic distance was the primary reason that Latinas were separated from close female-centered networks, which interrupted the transmission of health-related beliefs and behaviors.

The absence of female support also presented barriers for childcare and receiving emotional support. For many Latinas, childcare after pregnancy has traditionally been provided by the extended family $(38,39)$. Thus, its absence may be a major barrier to physical activity among recently immigrant women $(24,26)$. Male partners may be reluctant to take care of children so women can exercise outside the home due to cultural beliefs about appropriate behavior for married women $(9,24)$ and fears about neighborhood safety (9). Increasing women's access to supportive females may alleviate such concerns, and compliment male support by providing encouragement and advice for diet, exercise, and weight issues that is based on personal experiences with pregnancy and the postpartum period.
A limitation of this study was that participants were a low-income volunteer sample of almost exclusively recent immigrant, Mexican women drawn from one urban location. Consequently, the findings cannot be generalized to women of other ethnic minority groups, those of higher socioeconomic status, or rural women. Nevertheless, many U.S. cities have a growing number of recent immigrants from Mexico (40), for which very little is known about the dietary and physical activities of pregnant and postpartum Latinas. Therefore, these qualitative findings have important implications for the development of intervention strategies and future research of similar populations.

Factors such as stress, mental health, and physical conditions were not fully explored as explanations of the utility of social support for initiating and maintaining health-related behaviors. Further research that directly links these and other underlying factors affecting the type, presence, or absence of social support would contribute to understanding how social support can be strengthened in ways that promote women's health. While this study was limited by design (focus on linked pairs) to the analysis of individual interviews with a relatively small number of people, the results were supported by the findings of focus groups subsequently conducted with additional pregnant and postpartum Latino women (30). This process of triangulation lends an additional validity check to the findings of this study.

Several gaps in social support exist for many recently immigrated, low income Latinas that may influence their health-related behaviors during and after pregnancy. However, existing strengths in the family, including family cohesion and interdependence, may be enhanced to help individuals make a cognitive link between the importance of social support and healthy behavior. Findings from this, and previous, research $(9,22-26,28)$ suggest that pregnant and postpartum Latinas could benefit from social support interventions that incorporate community and family-based strategies to change and sustain healthy behaviors over time.

Influencing women's diets on a long-term basis may occur more readily by educating women and their supportive others, particularly husbands, rather than by focusing on women only. In the present study, husbands who were the primary social influence on women's dietary behavior had also lived longer in the U.S. than their wives. These men had more influence on women's dietary acculturation than did other people or sources, which 
contributed to healthy and unhealthy eating practices. Future studies, with a larger sample of dyads may further confirm and extend the findings from the current study by investigating how the influence of social support on weight, eating, and exercise patterns may change for Latinas and their families during the acculturation processes affecting each family member.

Broad-based, family-oriented interventions may have far-reaching appeal and health benefits. Research shows that Latinos who have histories of childhood physical activity also report vigorous physical activity as adults (25). In the present study, Latino husbands and wives who exercised together (i.e., soccer, playing in parks) liked to include their children in activities. Thus, programs whereby children and families receive instruction on, and opportunities to exercise may promote healthy intergenerational habits over time. Similar positive consequences may result from family programs that focus on dietary practices and weight maintenance. Thus, culturally relevant intervention strategies should focus on family health in an effort to improve the individual health beliefs and behaviors of Latinas and their close others on a long-term basis. Ultimately, much more attention is warranted for community-based participatory research that increases understanding of how culturally relevant and effective community-based programs and policies that strengthen and extend existing social support networks can contribute to maintaining health promoting behavior among immigrant Latino families in low resource communities.

\section{ACKNOWLEDGMENTS}

This study was based on research conducted by Promoting Healthy Lifestyles Among Women, a community-based research project conducted in affiliation with the Detroit Community - Academic Urban Research Center with funding and other support provided by the Centers for Disease Control and Prevention, Division of Nutrition and Physical Activity, Grant No. U48/CCU515775/SIP10 and the W.K. Kellogg Foundation Community Health Scholars Program. Support for this analysis was provided by the W.K. Kellogg Foundation Health Disparities Scholars Program, and the National Institute of Mental Health Psychosocial Factors in Mental Health and Mental Illness Training Program. The authors wish to thank the project Steering Committee organiza- tions, representations and community residents, and graduate research assistants for their participation in all phases of the project.

\section{REFERENCES}

1. Mokdad AH, Bowman BA, Ford ES, Vinicor F, Marks JS, Koplan JP. The continuing epidemics of obesity and diabetes in the United States. JAMA 2001;268(10):1195-200.

2. Flegal KM, Carroll MD, Ogden CL, Johnson DL. Prevalence and trends in obesity among US adults 1999-2000. J Am Med Womens Assoc 2002;288:1723-7.

3. Kieffer E, Carman W, Gillespie B, Nolan G, Worley S, Guzman R. Obesity and gestational diabetes among African American and Latino women: Implications for disparities in women's health. J Am Med Womens Assoc 2001;56:181-7.

4. Gregory KD, Kjos SL, Peters RK. Cost of noninsulindependent diabetes in women with a history of gestational diabetes: Implications for prevention. Obstet Gynecol 1993;81:782-6.

5. Williamson DF, Madans J, Pamuk E, Flegal KM, Kendrick JS, Serdula A. Prospective study of childbearing and 10-year weight gain in US White women 25-45 years of age. Int J Obes Relat Metab Disord 1994;18(8):561-9.

6. Boardley DJ, Sargent RG, Coker AL, Hussey JR, Sharpe PA. The relationship between diet, activity, and other factors, and postpartum weight change by race. Obstet Gynecol 1995;86(5):834-8.

7. Silverman BL, Rizzo TA, Cho NH, Metzger BE. Longterm effects of the intrauterine environment: The Northwestern University Diabetes in Pregnancy Center. Diabetes Care 1998;21:B142-9.

8. Cogswell ME, Perry GS, Schieve LA, Dietz WH. Obesity in women of childbearing age: Risks, prevention, and treatment. Primary Care Update OB/GYNS 2001;8:89-105.

9. Kieffer EC, Willis SK, Arellano N, Guzman R. Perspectives of pregnant and postpartum Latino women on diabetes and physical activity, and health. Health Educ Behav 2002;29(5):542-56.

10. Kieffer E, Salabarría-Peña Y, Odoms-Young A, Willis S, Baber K, Guzman R. Promoting Healthy Lifestyles among Women/Promoviendo Estilos de Vida Saludables entre Mujeres: A Community-Based Participatory Resarch Project Affiliated with the Detroit Urban Research Center. Annual Meeting of the American Public Health Association, Atlanta, GA, October, 2001. (Abstract: Conference Proceedings).

11. Dunkel-Schetter C, Sagrestano LM, Feldman P, Killingsworth C. Social support and pregnancy: A comprehensive review focusing on ethnicity and culture. In: Pierce GR, Sarason BR, Sarason IG, editors. Handbook of social support and the family. New York: Plenum, 1986:375412.

12. Orr ST. Social support and pregnancy outcome: A review of the literature. Clin Obstet Gynecol 2004;47(4):842-55.

13. Cohen S, Syme S. Issues in the study and application of social support. In: Cohen S, Syme S, editors, Social Support and Health. Orlando, FL: Academic, 1985:3-20.

14. Sarason BR, Sarason RG, Pierce GR. Traditional views of social support and their impact on assessment. In: Sarason B, Sarason I, Pierce G, editors, Social Support: An Interactional View. New York: Wiley, 1990:1-26.

15. Thoits PA. Stress, coping, and social support processes: Where are we? What next? J Health Soc Behav 1995; extra issues:53-79. 
16. Dunn CL, Pirie PL, Hellerstedt WL. The advice-giving role of female friends and relatives during pregnancy. Health Educ Res 2003;18(3):352-62.

17. Hutchins E, DiPietro J. Psychosocial risk factors associated with cocaine use during pregnancy: A case control study. $\mathrm{Ob}$ stet Gynecol 1997;90(1):142-7.

18. Lindenberg CS, Strickland O, Solorzano R, Galvis C, Dreher $\mathrm{M}$, Darrow VC. Correlates of alcohol and drug use among low-income Hispanic immigrant childbearing women living in the USA. Int J Nurs Stud 1999;36(1):3-11.

19. Feldman PL, Dunkel-Schetter C, Sandman CA, Wadhwa PD. Maternal social support predicts birth weight and fetal growth in human pregnancy. Psychosom Med 2000;62:715-25.

20. Keefe SE, Padilla AM, Carlos ML. The Mexican American extended family as an emotional support system. Hum Organ 1979;38:144-52.

21. Vega WA. Hispanics in the 1980s: A decade of research. $J$ Marriage Fam 1990;52:1015-24.

22. Balcazar H, Krull JL, Peterson G. Acculturation and family functioning are related to health risks among pregnant Mexican American women. Behav Med 2001;27(2):6270 .

23. Collins R, Lee RE, Albright CL, King AC. Ready to be physically active? The effects of a course preparing low-income multiethnic women to be more physically active. Health Educ Behav 2004;31(1):47-64.

24. Evenson KR, Sarmiento OL, Macon ML, Tawney KW, Ammerman AS. Environmental, policy, and cultural factors related to physical activity among Latina immigrants. Women Health 2002;36(2):43-57.

25. Hovell M, Sallis J, Hofstetter R, Barrington E, Hackley M, Elder J, Castro F, Kilbourne K. Identification of correlates of physical activity among Latino adults. $J$ Community Health 1991;16(1):23-36.

26. Kieffer E, Willis S, Odoms-Young A, Guzman R, Allen A, Two Feathers J, Loveluck J. Reducing disparities in diabetes among African American and Latino residents of Detroit: The essential role of community planning focus groups. Ethn Dis 2004;14(3, Suppl 1):S127-S137.

27. Sanderson B, Littleton MA, Pulley L. Environmental, policy, and cultural factors related to physical activity among rural, African American women. Women Health 2002:36(2): 75-90.
28. Sanders-Phillips K. Correlates of healthy eating habits in lowincome Black women and Latinas. Prev Med 1994;23:781-7.

29. Israel BA, Lichtenstein R, Lantz P, McGranaghan R, Guzman AA, Softley JR, Maciak B. The Detroit community - academic urban research center: Development, implementation, and evaluation. J Public Health Manage Pract 2001;7(5):1-19.

30. Kieffer E, Salabarría-Peña Y, Odoms-Young A, Willis S, Baber K, Guzman R. The application of Focus Group Methodologies to community-based participatory research. In: Israel B, Eng E, Schulz A, Parker E, editors. Methods for conducting community-based participatory research in public health. Jossey-Bass, in press, Spring.

31. U.S. Census Bureau; 2000 Census of Population and Housing; Summary File 3; generated by Michigan Metropolitan Information Center, Wayne State University, April 2002.

32. Muhr T. Atlas.ti, Version 4.1. Berlin: Scientific Software Development, 2000.

33. Strauss A, Corbin J. Basics of Qualitative Research: Grounded Theory Procedures and Techniques. Newbury Park, CA: Sage, 1990.

34. Domian EW. Cultural practices and social support of pregnant women in a Northern New Mexico Community. $J$ Nurs Scholarshipip 2001;33(4):331-6.

35. Pearce CW. Seeking a healthy baby: Hispanic women's views of pregnancy and prenatal care. Clin Excell Nurs Pract 1998;2(6):352-61.

36. Gutierrez YM. Cultural factors affecting diet and pregnancy outcomes of Mexican American adolescents. J Adolesc Health 1999;25(3):227-37.

37. Clark L. La Familia: Methodological issues in the assessment of perinatal social support for Mexicans living in United States. Soc Sci Med 2001;53:1303-20.

38. Clark M. Health in the Mexican American culture. Berkeley: University of California Press, 1959.

39. Kay MA. Mexican, Mexican American, and Chicana childbirth. In: Melville M, editor, Twice a Minority: Mexican American Women. St. Louis, MO: Mosby, 1980:52-65.

40. U.S. Census Bureau. 2000 Census of Population and Housing: Summary File 3, PCT.20, generated by Government Documents Library, University of Michigan, Ann Arbor, MI USA: using American FactFinder http://factfinder.census.gov (August 2004). 